\title{
Yağ Tulumu: Bir Dönüşümüin Sosyolojik Boyutu
}

\section{Yă̆ Tulumu: The Sociological Dimension of a Transformation}

\author{
Elif Batu ${ }^{1}$ [C
}

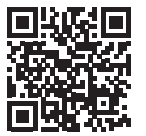

öz

Bu çalışma, Guy de Maupassant'ın ilk başyapıtı olan Boule de Suifin Türkçedeki dönüşümü bağlamında eserin farklı bir okumasını sunarken, sosyolojik koşullar ile çeviri olgusu arasındaki ilişkileri de ortaya koymayı amaçlamaktadır. Diğer bir deyişle, Boule de Suif in çizgi roman olarak Yağ Tulumu'na dönüşümünü sosyolojik yaklaşımın bakış açısıyla ele almak amacındadır. Çalışma, Itamar Even-Zohar'ın "çoğuldizge", "merkez-çevre ilişkileri " ve " kültür repertuvarı " kavramlarını açıklamakta ve bu kavramlar doğrultusunda çevirinin Türkiye'deki ve Türk toplumundaki anlamını, önemini vurgulamaktadır. Ortaya çıkışını ve yapısını açıkladıktan sonra, genel olarak çizgi romanların sosyo-kültürel yönleri hakkında özlü bilgi vermektedir. Yazarına dair özet bilgi vermekle birlikte, Boule de Suif in dönüşümünün ana nedeni olarak görülebilecek olan içeriğine odaklanarak, metnin hem toplumsal hem de evrensel yönlerine ve Yağ Tulumu'nun küresel çağın popüler kültüründeki işlev ve önemine işaret etmektedir. Maupassant'ın Boule de Suifi üzerine Türk dilindeki az sayıda, ender çalışmalardan biri olmasını sağlayan özellikleri açııından da bu eserin, ayrıca ilgi çekici olacağı düşünülmektedir.

Anahtar kelimeler: Çeviribilim, çoğul dizge kuramı, çizgi roman, Boule de Suif, Yağ Tulumu

\section{ABSTRACT}

This study investigates the relationship between sociological conditions and the fact of translation while also offering a novel reading of Boule de Suif by Guy de Maupassant in relation to its transformation into Turkish as Yağ Tulumu in the form of comic book adopting a sociological perspective. This study investigates the idea of the literary poly-system, relations between the center and periphery, and Sorumlu yazar/Corresponding author: Elif Batu (Dr.), and importance of translation in Turkey and Turkish society in relation to these notions. It describes the socio-cultural aspects of the medium of comics in general after discussing its emergence and structures. The social and universal aspects of Boule de Suif are examined by focusing on contents that can be seen as the genesis of the transformation of the text. It also outlines the function and importance of Yağ Tulumu in popular culture in the global age and; at the same time, it provides brief information on the famous author of the text. This is one of the few studies on Maupassant's Boule de Suif in Turkish.

Keywords: Translation studies, theory of literary poly-system, comics, Boule de Suif, Yağ Tulumu 


\section{EXTENDED ABSTRACT}

This study analyzes the conditions under which and for what purposes translations are conducted, from a sociological point of view through a focus on the example of the transformation of Boule de Suif, Maupassant's first masterpiece, into Yă̆ Tulumu in Turkish, drawing attention to the meaning and importance of this transformation in the sociological context. However, in the examination of the work, a product-oriented approach was taken in preference to a processoriented one; the work is handled along the axis of its essence and content rather than that of its form and structural features. Because a translation comes into being within a relationship to the social and cultural environments in which it is produced and read, this study adopts Itamar Even-Zohar's theory of literary poly-system and it also uses the concepts of center and periphery relations and cultural repertoire to clarify some facts in Turkish literary history. After briefly noting the development of the role of translation in Turkish culture and literature in its chronological development, the study examines how a new culture was deliberately created in Turkish history in the 1930s and how the translation movement begun at this direction could serve as an example for the theory of literary poly-system. The birth of the medium of comics, its structure and genres, and the ways in which it functions are presented. Moreover, its place and function in popular culture in the global age, together with the related social and cultural aspects, are also shown. Information on Guy de Maupassant and his work Boule de Suif is involved, including discussion of the life and identity of the author and his method and writing style. The translation of Boule de Suif into Turkish is explained, and the facts that have caused its change of genre and language to a comic book in Turkish under the title Yă̆ Tulumu are discussed. The content of the work in relation to both its transformation and its universal appeal is described. The plot, the characters, and the key details are highlighted. At the end of the study, it is made clear that no act of translation can occur casually or randomly. The introduction and circulation of translations also continues in line with certain social, ideological, and political goals along with the major translation movements that have been initiated for determined reasons, such as creating a new language, culture, and literature, as in the example of Turkish history. Thus, translation fulfills its task through products preferred within popular culture in the current global age, which are easy to access and have immediate impact on people. If it is accepted that visuality has a strong and permanent effect on human perception, the importance of the comic in this century as a genre with both literary and visual qualities becomes clear. Because mass media and art, including comics, are usually no considered apart from their social and cultural context, it is easy to conclude that are produced for political and ideological purposes as well as for economic ones. In this context, the transformation of the literary classics can be more clearly seen. To put it another way, a summary of the aims and justifications of this movement of classical works shows itself when the reasons for the transformation of Boule de Suif, the first masterpiece of Maupassant, into Yağ Tulumu are 
explored. Because the universal nature of the story lends itself to being used as a tool to awaken social consciousness, the work was made into a comic, one of the most effective and common tools of popular culture. Thus, when the type and qualities of the Yağ Tulumu are evaluated, it can be seen that it serves a counter to the dominant, hegemonic ideology. This study also suggests that comics containing picture and visual content can be used to awaken and enlighten public opinion, in contrast to the previous use by the upper classes who were able to manage illiterate lower classes using images in accordance with their own ends. 


\section{Yă̆ Tulumu: Bir Dönüşümün Sosyolojik Boyutu}

Her olgu içinde bulunduğu koşullara bağlı olarak varlık bulmaktadır. Doğa olaylarının sebep ve sonuç bağlamında gerçekleştiği göz önünde bulundurulduğunda sanat yapıtları ve çeviriler gibi insan ürünlerini de aynı bağlamda değerlendirmek olasıdır. Çevirilerin neden, hangi koşullarda ve hangi amaçlarla gerçekleştirildiğini çözümlemenin hem çevrilen özgün yapıtların hem de çeviri ürünlerin yerini ve değerini saptamanın ön koşulu olduğu söylenebilir.

$\mathrm{Bu}$ çalışma, en sevilen klasik öykücülerden birinin yine en sevilen yapıtlarından belki de en önde geleninin, Maupassant'ın ilk başyapıtı Boule de Suif' in Yă̆ Tulumu'na dönüşümünün sosyolojik boyutuna dikkat çekmek amacındadır. Zira eser, tüm zamanlara hitap edebilmeyi ve sayısız dillere çevrilmeyi başardığı gibi, Türkçe'ye bütüncül bir değişim de geçirerek farklı bir türde, bu defa çizgi roman formunda, yeniden girmiştir. Boule de Suif' in Yă̆ Tulumu'na dönüşecek kadar beğenilmesinin, tercih edilmesinin nedenleri ve özgün haliyle birlikte, çizgi roman formunun da ayrıca önemi küresel çağın toplumsal ve kültürel koşulları bağlamında değerlendirilecektir. İnceleme gerçekleştirilirken süreç odaklı değil, ürün odaklı bir yaklaşım benimsenecektir. Ürün ise biçiminden ve yapısal özelliklerinden çok, özü, içeriği ekseninde ele alınacaktır.

Araştırmanın ilk bölümünde, yöntemsel yaklaşım kapsamında Itamar Even-Zohar'ın geliştirdiği çoğuldizge kuramındaki merkez-çevre ilişkileri, kültür repertuarı ve çevirinin Türkiye'deki ve Türk toplumundaki anlam ve önemi ele alınarak, çizgi romanın genel anlamda toplumsal ve kültürel yönü vurgulanacaktır. Ayrıca, eserin yazarına da yer verildikten sonra Boule de Suif' in içeriğine ve evrensel yönüne (dönüşümünün ve dolaşımının nedeni olarak görülebilecek kilit noktanın burada olduğu düşünülebilir) değinilerek, Yağ Tulumu'nun küresel çağın popüler kültürdeki işlevi ve önemi incelenecektir.

\section{Amaç ve Yöntem}

Çeviri hem bir edim hem de bir ürün olarak değerlendirildiğinde sosyal bağlamdan ayrı düşünülememektedir. Çeviri ediminin, çevirinin türü ve aşaması ne olursa olsun belli bir topluma ait bir birey tarafından gerçekleştirildiği açıktır. "Çeviri olgusunun kendisi de çevirilerin seçimini, üretimini, dağıtımını ve bunlara paralel olarak çevirinin kendine ait stratejilerini de belirleyen sosyal kurumlarla doğrudan bağlantılıdır." (Wolf, 2007: 1) Diğer bir deyişle, çeviri üretildiği ve okunduğu sosyal ve kültürel ortamlarla ilişkisinin sonucunda var olmaktadır (Venuti, 1995: 18).

Bu çalışmada, çeviri olgusu ve çeviri ürünler söz konusu olduğundan, ilk olarak 'çoğul dizge kuramı'na yer verilmektedir. Yapıtların çeviri yoluyla taşınmasının nedenlerini açıklamak için edebiyatı çok yönlü bir çoğul dizge olarak ele aldığı kuramında Itamar Even-Zohar, edebiyat çoğul dizgesi içindeki merkez-çevre ilişkilerine ve kültür repertuarı kavramlarına dikkat çeker. Çeviri edebiyatı da çoğul dizgenin içindeki dizgelerden biri olarak görür ve bir ana dizgenin içine çeviri edebiyatın girmesine ve orada merkezi konumda bulunmasına, hedef edebiyatın 
repertuarındaki boşluklar, eksiklikler nedeniyle geri planda (çevre konumunda) olmasını neden gösterir. Even-Zohar'in repertuar kavramıyla işaret ettiği, herhangi bir kültürel ve yazınsal ürünün hem ortaya çıkarılmasını hem de kullanımını yöneten kurallar ve materyaller bütünüdür; yani yazınsal faktörler, sözlük ve dilbilgisiyle birlikte çeviriler de dâhil olmak üzere tüm kültürel ürünleri meydana getiren sosyal, kültürel ve ekonomik faktörlerdir (1990: 17, 39, 40, 47, 207).

Çeviriyi sosyal bir eylem olarak gören André Lefevere de yazınsal ve kültürel metinlerin hem telif hem de çeviri yoluyla üretimi sürecinde doğrudan belirleyici rol oynayan sosyal güçlere işaret eder. Belirli bir ideolojiyle hareket eden, alanla ilişkili bireyleri, toplulukları ve kurumları himaye ederek yöneten bir sistemden söz eder. Çeviri yoluyla taşınmanın sosyal boyutunu açıklayan Lefevere, Pierre Bourdieu'nün 'kültürel sermaye' ve 'ekonomik sermaye' kavramlarını da ele alarak görüşlerini temellendirir. Çevirilerin kültürden kültüre olduğu kadar, belli bir kültürde de kendi içindeki dağıtımında hem itici güç hem de taşınılan, dağıtılan faktör olarak kültürel sermayeyi görür. Çevirilerin en son durumunu belirleyen etkenin ise ekonomik sermaye ve onu elinde tutan, yazınsal sistem içinde ayrıcalıklı konuma sahip birey ve kurumlar olduğunu söyler (1998: 41, 48).

Lawrence Venuti’nin vurguladığı gibi, çeviri; farklı kültürler için üretilen ideolojik temelli kimlikleri oluşturabilen ve de eleştirebilen, hedef dildeki ve kültürdeki değerleri ve geleneksel ölçüleri doğrulayabilen ya da onlara karşı çıkabilen bir olgudur (1995: 19). Almanya'daki Nazi rejimi sırasında çeviri alanında hüküm süren baskı ve sınırlamalarla çeviri olgusunun, çevirmenlerin ve çeviri üretiminin egemen ideolojiyi destekleyen bir araç konumunda bulunması (Wolf, 2007: 15), Venuti'nin bu sosyolojik boyutlu çeviri tanımına bir örnek niteliğindedir. Ayrıca, bu durum, Pierre Bourdieu'nün bir kültürel ürünün başarısının, onun belli bir toplum içindeki konumuna ve değerine bağlı olduğu yolundaki tespitine de örnek teşkil eder niteliktedir (Wolf, 2007: 16).

\section{Bulgular}

\section{Türk Kültüründe ve Edebiyatında Çevirinin Yeri}

Eldeki verilere göre, ilk Türkçe’ye çeviriler 9. yüzyılda Uygur Türklerinin Budizm'le ilgili metinleri Türkçe’ye çevirtmeleriyle başlamıştır. Aynı zamanlarda Selçuklu Türklerinin de dini, felsefi, bilimsel ve yazınsal eserleri Arapça ve Farsçadan çevirttikleri bilinir (Gürsel, 1995: 321). Türk dilindeki ilk resmi çeviri etkinliği III. Ahmet (1703-1730) döneminde yirmi beş üyeli bir çeviri kurulu oluşturularak başlatılmıştır. Bu kurul, hepsi Arapçadan olmak üzere çeşitli tarih kitaplarını ve Aristoteles'in Fizik'ini çevirmiştir (Gürsel, 1995: 320).

1839 yılında Tanzimat'la birlikte batılılaşmanın resmen başlaması büyük çaplı çeviri etkinliklerinin de başlamasına yol açtı. Bu dönemden itibaren büyük bir çoğunluğu Fransız olmak üzere Batı yazınından eseler Türkçeye çevrilmeye başlandı (Karantay, 2008: 48, 49). 
Örneğin, 1880-1896 yılları arasındaki on altı yılda Goncourt Kardeşler, Alphonse Daudet, Emile Zola ve bu incelemeye konu olan yapıtın yazarı Maupassant gibi realist ve natüralist yazarlardan çeviriler yapıldı (Kudret, 2008: 21).

Ancak en verimli çeviri etkinlikleri Cumhuriyetin ilanıyla ve Atatürk devrimleriyle yeni Türk dilinin ve kültürünün oluşmaya başladığı dönemde görülmeye başladı. Bu dönemde yayıncılığa özel bir önem verilerek, 1939 yılında Birinci Türk Neşriyat Kongresi toplandı. Dönemin yayıncılığının içinde bulunduğu durumun ve yayıncılığın sonraki dönemlerde izleyeceği yolun saptanması, yayınlanacak telif eserlerin ve çevrilecek yapıtların bir program dâhilinde belirlenmesi planlandı (Tahir Gürçağlar, 2008: 37).

Çeviri etkinliklerine yönelik böyle girişimlerin doruk noktasına ulaşması ise 1940'ta Tercüme Bürosunun kurulması ile gerçekleşti. Dönemin milli eğitim bakanı Hasan Ali Yücel önderliğinde başlatılan çalışmalarda Batı klasiklerinden oluşan bir liste hazırlandı ve Tercüme Bürosundan beklenen listedeki kitapları çevirmenlere dağıtmak, çevirileri denetlemek ve yayın işlerini planlı programlı bir şekilde yürütmekti. Tercüme Bürosunun görevlerinin de gösterdiği gibi, çeviri konusundaki beklentiler ve tavırlar netti. Çeviriye yüklenen ana işlevler Türk dilini zenginleştirmesi ve batı kültürünü aktararak eğitici bir görev üstlenmesiydi (Tahir Gürçağlar, 2008: 38, 39).

Cumhuriyetin ilk yıllarından ve özellikle de 1928'deki Harf Devrimi'nden sonra yalnızca resmi değil, özel yayıncılığın da devletten mali destek gördüğü bilinmektedir. Devlet himayesi üç boyutlu bir olgudur: İdeolojik boyut, ekonomik boyut ve statü boyutu. İdeolojik boyut biçim ve konu seçimini ve de geliştirilmesini destekleyebilen ya da kısıtlayabilen boyuttur. Ekonomik boyuttan kasıt, yazar ve çevirmenlerin hamiye bağımlı olmaları durumudur. Statü boyutunun anlamı ise himaye altında olmanın belli bir yaşam tarzı ve statü simgesi haline gelmesidir. 1930'lar Türkiye'sinde çeviri ve yayın alanında devlet himayesinin tüm bu üç boyutta da sürdüğü ve Tercüme Bürosu'nun da bu himayenin bir uzantısı olarak ortaya çıktığı bilinmektedir (Tahir Gürçağlar, 2008: 40).

Görülüyor ki, başlatılan çeviri hareketiyle Batı kültüründen eserleri Türkçeye kazandırmak ama bununla birlikte ulusal kültürün oluşumuna da katkıda bulunmak amaçlanmıştı. Diğer bir deyişle, yeni Türkiye Cumhuriyeti için ithal yoluyla yeni bir edebiyat ve kültür repertuvarı oluşturulması ve zaman içinde de bu repertuvarın ulusal bir repertuvara dönüşmesi planlanmıştı. $\mathrm{Bu}$ çeviri hareketi bilinçli ve planlıydı; tabandan oluşan bir hareket değildi. Dönemin diğer kültürel girişimleri gibi, bu hareket de doğrudan devletin oluşturduğu bir himaye sistemi içinde var olmuştu (Tahir Gürçağlar, 2008: 41, 42).

Türk tarihinde planlanarak oluşturulan bir kültür ve başlatılan çeviri hareketinin, Şehnaz Tahir Gürçağlar'ın da belirttiği gibi, Even-Zohar'ın çoğuldizge kuramına örnek teşkil eder nitelikte olduğu söylenebilir. Even-Zohar'a göre, devingen ve değişken kültür çoğuldizgesinde gerçekleşen değişimlerin tamamı rastlantısal ve kendiliğinden değildir, bilinçli ve planlı bir çabanın ürünü de olabilir. Kültürü oluşturulan repertuarın bazı kişi ve kurumlarca yeniden 
yapılandırıldığı dönemler görülebilir. Bu, mevcut repertuarın kısmen değiştirilmesi, geliştirilmesi şeklinde olabileceği gibi repertuarın tamamen değiştirilip yerine bir yenisinin oluşturulması yoluyla da gerçekleşebilir. Oluşturulan yeni repertuarlar ya icat edilerek özgün bir biçimde ya da dışarıdan ithal edilip özümsenerek meydana getirilir. Ancak, özellikle edebiyat çoğuldizgesi düşünüldüğünde özgün yaratımın oldukça zor ve uzun bir süreç olduğu, bunun yerine diğer kültürlere ait repertuvarların benimsenip hedef kültüre uyarlanmalarının daha kolay bir yöntem olduğu ortadır. Bu ithal yönteminde birincil görev de çevirilere düşer. Planlı çeviri hareketlerinde çevrilmek üzere seçilen metinler ve bunların çevriliş biçimleri, oluşturulmak istenen kültür repertuarını belirgin derecede yansıtır (2008: 43). Even-Zohar'ın varsayımına göre tekrar ifade edilecek olursa; çeviri edebiyat 'merkez' konumunda olduğunda çoğuldizgenin merkezinin biçimlendirilmesine etkin olarak katılıyor demektir. Böylelikle, çeviri edebiyat büyük ölçüde yenilikçi güçlerin bir parçasıdır (Paker, 2008: 28). Türk tarihinde de özellikle 1940 sonrası çeviri hareketiyle gerçekleşenin bu olduğu söylenebilir.

Elbette, Türkçeye çeviriler 1966 yılının sonuna dek varlığını sürdüren ve bini aşkın yapıt üretip yayınlayan Tercüme Bürosu (Karantay, 2008: 52) ile sınırlı kalmamıştır. Yine bir kültür repertuarı oluşturacak boyutta yeni bir çeviri hareketi meydana gelmemiş olsa da, çok sayıda resmi ve özel yayınevleri ve kitle iletişim araçları tarafından gerçekleştirilen çeviriler, küresel ortak kültürün oluşumunda vazgeçilmez bir araç ve çağdaş popüler kültürün ayrılmaz bir parçası olarak varlığını sürdürmektedir.

\section{Çizgi Roman ve Toplumsal-Kültürel Yönü}

\section{Çizgi Roman}

En genel anlamda tanımlanacak olursa, Levent Cantek'in saptamalarından hareketle, çizgi roman metin ve resim gibi birbirinden çok farklı iki olgunun belli bir kurgu çerçevesinde birleştirilmesiyle oluşan bir yazın ve anlatım sanatıdır. Yüksek oranda görsellik içeren bu yazılı metin türü de bütün yazınsal metinler gibi anlatımsallık ve yaratıcılık özellikleri göstermektedir. Ancak, bir resim ve metin bileşiminden çizgi roman olarak söz edebilmek için bu ürünün basılı olması da gerekir (2012: 21, 22). Cantek'in ilettiği üzere, çizgi roman çizgi bantın gelişmesiyle var olmuş bir tür olsa da bu ikisi arasında önemli farklılıklar bulunduğunu da ayrıca hatırlamak gerekir. Çizgi romanın öncelikle, kendi iletişim araçlarını yaratarak çizgi banttan ayrıldığı söylenebilir. Çizgi bantlar çoğunlukla gazete ve dergilerin bir köşesinde yer alarak gündelik ve mizah ağırlıklı bir içerikle varlığını sürdürürken, çizgi romanlar dergialbüm ve kitap formlarında basılarak, yalnızca onun başarısına bağlı bir ticari beklentiyle bir sonraki sayının satın alınmasını sağlayacak ilgi ve merakı sürdürmeye çalışarak var olur. Çizgi bantlar yalın ve güncel bir temayla sınırlıyken, çizgi romanlar çok daha genel, evrensel veya ulusal anlamlar barındırır (2012: 22-27), böylelikle ideolojik ve politik anlamda da daha önemli bir işleve sahiptir. 
Çizgi romanın, gelişim döngüsünü tamamlayıp bugünkü son şekline ulaşırken iki ana türde oluşageldiğini de belirtmek gerekir: Kahraman Çizgi Romanı ve Yaratıcı Çizgi Romanı. Yine Cantek' in işaret ettiği gibi, Kahraman çizgi romanları herhangi bir anlatıyı çizgi roman teknikleriyle iletmek üzerine kuruludur. Anlatılar genellikle aksiyon kurgusuyla yansitılır ve aralara kurguyu desteklemek ve eğlendiriciliği arttırmak amacıyla mizah öğeleri serpiştirilir. Burada öyküyü anlatan kişinin okur için önemsiz olduğu söylenebilir; ağırlık macera ve aksiyon içeren anlatı üzerindedir. Kahramanlar, sıradan insanlar, iyiler ve kötüler olmak üzere üç ana gruba ayrılır ve aralarındaki ilişki son derece belirgindir. Bu özellik okurun kahramanlarla ve sunulanlarla özdeşleşmesini kolaylaştırır (2012: 27, 28). Böylece, bu tür çizgi romanların politik ve ideolojik kontrol, etki veya propaganda aracı olarak kullanılmaya daha yatkın oldukları düşünülebilir. Yaratıcı çizgi romanları ise, daha çok 1960'lı yıllarda çizgi romanın artık bir sanat kimliği kazandığı dönemlerde ortaya çıkmaya başlamıştır. Cantek, belli bir yaratıcının yapıtı olan bu tür çizgi romanlarda karakterlerin ve öykülerin ağırlıkla gerçek yaşamla örtüşmekte olduğunu vurgular. Karakterler, klasik çizgi roman kahramanlarına özgü süper, doğaüstü ve fantastik özellikler taşımazlar; aksine, insana özgü her türlü davranışı sergilerler. Vurgu da olay örgüsü üzerine değil anlatıcı ve / veya karakterler üzerinedir. Çeşitli yabancılaştırma efektlerinin kullanımıyla okurun kendini karakterlerle ve öykülerle özdeşleştirmesi engellenmeye çalışılır. Ancak, son dönemlerde bu iki farklı tür arasındaki keskin sınırlar giderek ortadan kalkmakta ve türler birbirine yaklaşmaktadır. Özellikle de kahraman çizgi romanlarındaki 'süper kahraman', 'kusursuz kahraman' imajının bu yönde önemli değişimler geçirdiği ve gerçekçilik kazandığ görülmektedir (2012: 27-29).

\section{Çizgi Romanın Toplumsal-Kültürel Yönü}

Kültürel bağlamda düşünüldügünnde, çizgi romanların popüler kültürün ürünlerinden (araçlarından) biri olduğu söylenebilir. En genel anlamda, geniş halk kitleleri tarafından yaygın olarak kullanılmakta olan ve hızlı değişen, geçici nitelikli bir kültürü ifade eden popüler kültür, öncelikle gündelik yaşama özgü olan ve kısa süreli, değişken ve kolay tüketilen öğeleriyle varlığını sürdüren bir kültürdür. Cantek'in de belirttiği gibi, iletişim çağından önceki popüler kültürün hedef kitlesi, endüstri devrimi sonrası köyden kente göç eden ve üretimin tüm yükünü sırtlayan emekçiler sınıfıdır. Televizyon ile başlayan, internet ile doruğa ulaşan günümüz iletişim çağında ise artık tüm toplumsal sınıflara ait bireyler yaygın, küresel bir popüler kültürün ve onun ürünlerinin etkisi altındadır $(2012: 18,19)$.

Bu noktada, popüler kültür ile yönetici sınıf arasındaki ilişki görünür hale gelir. Günümüzde bireyler hem iletişim devrimiyle iyice güçlenen medyanın hem de küresel kapitalist sistemin dayattığı ekonomik kaygılar nedeniyle yoğun baskı altındadır. Bu durum da insanları, nesnel doğaları gereği ucuz, kolay tüketilebilir ve kolay erişilebilir olan popüler kültür ürünlerine eğilimli, hatta muhtaç hale getirmektedir. Bireyler bu ürünlerle oyalanarak, bir anlamda uyutulup, uyuşturularak var olan düzenin dayattığı yaşamlarını sürdürmeye devam ederler. Sonuçta bu ürünlerle sağlanan geçici rahatlamanın bireye, yaşamakta olduğu gerçek dünyanın 
koşullarını sorgulayıp onları değiş̧irmeye kalkışmaktan çok daha kolay bir seçenek sunduğu ortadadır. İnsanların gerçekler karşısında çaresiz hissettiklerinde kaçışlara yöneldikleri ve ikonlara (yaratılmış figürlere) sığındıkları bilinmektedir (Cantek, 2012: 18-20).

Popüler kültür ürünlerinin egemen güç ve yönetici sınıfı tarafından kullanıldığı hem eğlence hem de kontrol aracı olma görevlerini yine sürdürmekle birlikte bugün artık bağımsız bir sanat dalına dönüşmüş bulunan çizgi romanın, Cantek' in belirttiği üzere, mağara resimlerine ve orta çağ kiliselerine dayanan temelleri göz önüne alındığında da kendini gösterir. Resmin insanların okuma yazma bilmedikleri çağlarda anlamayı ve anlaşmayı sağlamak amacıyla kullanıldığı bilinir. Ortaçağa gelinip sınıf farklılıkları oluştuğunda, hala büyük bir çoğunluğu okuma-yazma becerilerinden yoksun olan halkın karşısında yönetici azınlığın okur-yazarlık gibi kendilerini farklı, ayrıcalıklı ve tekelleştirici kılan özelliklerinin altını çizer nitelikte eylemlerde bulunduğu da eldeki bulgularla sabittir. Örneğin, dini ayinler halkın günlük konuşma dilinden farklı bir dilde yapılmaya başlanır. Kilise duvarlarına kolay anlaşılan ve çabuk etki yaratan resimler yaptırılır. Ünlü ressamlar tarafından yapılan bu resimler çeşitli kopyalama yöntemleriyle giderek tüm kiliselere yayılır. Üst sınıflar halkı kontrol edebilmek için resmi ve görselliği bir araç olarak kullanmışlardır. Çünkü üst sınıfların dünya görüşüne ve seçkin niteliklerine hitap edebilen yazıya karşın, görselliğe dayalı araçlar halkın görüşüne ve diline hitap etmeye daha elverişlidir. Matbaanın keşfinden ve yaygınlaşmasından sonra, resimlerin basılı ürünler olarak halka ulaşımı daha da kolaylaşmıştır. Kilise de insan bilincinde yazıdan daha etkili olan resmi bir propaganda ve eğitim aracı olarak kullanmıştır $(2012: 17,18)$. Dolayısıyla, resimli olması nedeniyle diğer edebiyat ürünlerine oranla daha kolay anlaşılır ve daha eğlendirici olduğundan daha büyük kitlelerce tercih edilen çizgi romanın günümüzdeki bu halini almasında belki de en büyük etkenin, orta çağ kilisesinin cahil halka Hristiyanlığı öğretmek için kullandığı, yazı da içeren resimli propaganda kâğıtları olduğu söylenebilir.

Ancak, popüler kültür ürünlerinden ve çizgi romandan iktidarı elinde bulunduranlar kadar buna karşı çıkanların da yararlanabileceği hatırlanmalıdır. Bu nedenle, çizgi romanlar popüler kültür içinde değerlendirilirken tümüyle egemenlerin veya tümüyle muhaliflerin amaçlarına hizmet ettiği yolunda bir genellemede bulunmak olası değildir. Yalnızca, çizgi romanların hedef kitleye, çoğunlukla da gençlere ulaşmada en hızlı ve etkili araçlardan biri olduğu savunulabilir. Çizgi romanların, özellikle de iletişim çağı öncesi dönemlerde, hedef kitleye hızlı ve etkili bir biçimde ulaşabilme aracı olarak değişik dönemlerde, farklı zümreler tarafindan farklı amaçlarla kullanıldığı söylenebilir. Diğer bir deyişle, çizgi romanlar farklı tarihsel dönemlerdeki farklı politik durumlara göre farklı yaklaşımlar ortaya koyabilmektedir. Çizgi roman doğası gereği kolay tüketilebilen, basit ve net göndermeler içeren ve popüler kültürün hedef kitlesi için rahatlıkla erişilebilen bir konumda bulunduğu için bu türün yalnızca, egemen gücün bir propaganda ve kontrol aracı olarak değerlendirilmesinin yanlış olacağı unutulmamalıdır. Üstelik her ne kadar bu tür amaçlara hizmet etse de, çizgi romanın nihai alımlanması ve etkileri yine okura bağlıdır. Yapıtın iletisi okurda tamamlanır, okurun da bu 
karşılıklı iletişime etkin (aktif) olarak katılması gerekir. Çizgi roman aracılığıyla sunulanlar bir anlamda okur ile yeniden kurgulanır. Oysa popüler kültürün diğer araçlarından sinema ve televizyon gibi kitle iletişim araçları karşısında okur ya da izleyici çizgi romana kıyasla daha edilgen (pasif) bir konumdadır. Bu nedenle, sinema ve televizyon gibi araçların kitleleri yönlendirmekte çok daha güçlü ve etkili olabildikleri, çizgi romanın bu araçların yanında daha masum kaldığı söylenebilir.

\section{Guy de Maupassant ve Boule de Suif (Yă̆ Tulumu)}

\section{Guy de Maupassant}

Fransız gerçekçileri arasında yapıtları Emile Zola'dan sonra en çok baskı yapan ikinci gerçekçi ve doğalcı yazar olarak anılan Guy de Maupassant'ın (1850 - 1893), zamanında olduğu kadar şimdilerde de dünya genelinde en çok sevilen kısa öykü yazarlarından biri olarak klasikleştiği bilinmektedir.

Kırk üç yıllık kısa ömrüne altı roman, üç yüz kadar kısa öykü, yolculuk-gezi anıları ve gazete makaleleri sığdıran yazar, başarısının büyük ölçüde, ustası ve yakın dostu Flaubert'den aldığı eğitimden kaynaklandığını sıklıkla dile getirmekten çekinmemiştir. "Tüm duyarlılığını, sanatın bir sabır işi olduğu bilincini ve 'biçem gibi olmayan biçem' inin oluşmasını" (İnce, 2001: 211) Flaubert'e borçlu olduğunu belirtmiştir.

Maupassant'1n öykülerinin bu çağa dek uzanan böyle bir beğeniyi nasıl elde ettiği irdelendiğinde ilk göze çarpan, yapıtlarına egemen olan çok yönlülük olur. Doğduğu topraklardaki günlük yaşamın dramlarını, yakından tanıdığı Normandiya' 1 köylüleri, balıkçıları, yerli esnafı, onların geçim sıkıntılarını, yoksulluklarını, kurnazlıklarını, dalaverelerini, küçük hesaplarını, doğayı ve denizi olduğu kadar, kenti, kent soylularının çıkarcılıklarını, bencilliklerini, önyargı ve takıntılarını ince bir alayla anlatır (İnce, 2001: 211). Yetkin sanatında çok yönlülükle birlikte, yüklü bir gözlem birikimi, insan ruhunun en gizli yönlerini dahi açık edecek kadar ince detaylar ve bunları ifade etmekten çekinmeyen bir cesaretin yanı sıra derin bir karamsarlık, hüzün ve şefkat bir arada kendini göstermektedir.

Ustalığının bir diğer göstergesi, Esma İnce'nin de işaret ettiği gibi, yalın, kısa, öz ve yapmacıksız fakat çarpıcı biçemidir. Sanatın doğanın bir kopyası olması gerektiğini savunan doğalcılık akımını bir ölçüde kabul etmekle birlikte, sanatçının gerçek olduğu için her şeyi değil, konusuna yararlı olmayanları eleyerek olayın en tipik, en özgün yanını günışığına çıkarmasının sanat olduğunu savunmuştur. Maupassant'ın yazın dünyasında moda ne olursa olsun, tüm yapıtlarında gözlemlenebilen bir tercihi vardır: Gerçeklerle örtüşen bir olay ve gerçek yaşamın tam içinden çıkıp gelmiş bir kahraman. İşte, bunun da tüm zamanlarda beğeni topladığ1 açıktır (2001: 212). Yazarın tutumuna belki de en güzel örnek; bu incelemeye konu olan, diğer öykülerinden farklı olarak içerdiği yaklaşık elli sayfayla daha çok bir novella özelliği gösteren, 1880 yılında yayınladığı ilk başyapıtı Boule de Suif' dir. 
İlgili bölümde evvelce de belirtildiği gibi, Tanzimat'la 1839 yılında Türk dilinde ve edebiyatında çığır açan nitelikte bir çeviri hareketi başlamıştı. Bu hareket dâhilinde Maupassant Türkçeye ilk kez 1890 yılında Ziynet (La Parure) ve Yolda (En Chemin) adlı öyküleriyle girmiştir. Boule de Suif ise ilkin, 1940 yılında Tercüme Bürosu'nun kurulmasıyla başlayan Türk tarihindeki ikinci çeviri hareketi kapsamında, Hasan Ali Yücel'in katkılarıyla Milli Eğitim Basımevi tarafından 1946 yılında Tombalak adıyla Nermin Sankur'un çevirisiyle Türkçeye kazandırılmıştır. Sonraları, 1958'de Kartopu adıyla Tahsin Yücel çevirisiyle Varlık Yayınevi tarafından, 1970'de Ferid Namık Hansoy çevirisiyle Seçilmiş Hikâyeler I, II başlıklı antolojinin içinde yer alarak İnkılap Kitabevi tarafından (Bogenç Demirel, 2008: 635-655) ve 1998'de Seçme Öyküler: Guy de Maupassant başlıklı seçkinin içinde yer almak üzere Mehmet Harmancı çevirisiyle Epsilon Yayınları tarafından Türk okuruyla buluşturulmuştur, bundan beri de çeşitli yayın evleri ve çevirmenler tarafından buluşturulmaya devam etmiştir, her zaman devam edeceği de açıktır. Ancak bu arada, 2010 Ocağında tam anlamıyla bir dönüşüme uğrayarak, Yă̆ Tulumu başlığıyla, Nur Simten Danışman'ın çevirisiyle Everest Yayınları Çizgi Serisi’nin 9. su olarak bu defa çizgi roman formunda okurunun karşısına çıkmış olması ayrıca dikkate değerdir. Her çeviri bir dönüşümdür ancak, bir yapıt türü değişecek boyutta bir dönüşümle tekrar okurlarıyla buluşuyorsa, bu onun evrenselliğinin belki de en somut göstergesidir. Boule de Suif' in Yă̆ Tulumu olarak yeniden yapılanacak kadar sevilmesinin, tercih edilmesinin nedenlerinin ise onun temasında; acı fakat gerçek olan ana mesajında bulunduğu söylenebilir. Bu noktada, yapıtın içeriğine değinmek yerinde olacaktır.

\section{Boule de Suif}

Maupassant Boule de Suif' de kendisinin de cephede bulunarak fiilen yaşadığı 1870 FransızAlman Savaşı döneminden bir kesit sunuyor. Öykü, Fransa'ya giren Alman askerleri karşısında geri çekilmek zorunda kalan Fransız askerlerinin Rouen kentinden geçişinin ve Almanların gelip kente yerleşmesinin uzun bir betimlemesiyle başlıyor.

Neredeyse tüm olay örgüsünün bir arabanın içinde ve oradaki on kişi arasında gerçekleştiği söylenebilir. İşgal edilmiş Rouen'den kaçan on yolcu Dieppe'e giden bir arabanın içinde yolculuk etmektedir. Yolculardan biri patronunun iflas etmesinden yararlanarak zengin olan bir şarap tüccarıdır. Yanında eşi de bulunmaktadır. Bir diğer yolcu da yaşlı bir pamuk tüccarıdır ve genç eşiyle birlikte yolculuk etmektedir. Arabada Normandiya'nın en eski ve soylu ailelerinden bir Kont ve Kontes karı koca daha vardır. 'A Arabanın dibine yerleşen bu altı kişi, toplumun paralı, güçlü, mutlu, din ve ilkelerine bağlı, ayrıcalıklı insanları arasındaydılar.” (Maupassant, 1946: 23) Bu varlıklı, soylu, güçlü, dinlerine ve ilkelerine bağlı, ayrıcalıklı altı kişiden başka arabada iki rahibe, Cornudet adında, baba servetini tüketmiş, işe yaramaz ve maceracı bir devrimci, cumhuriyetçi ve öyküde erdemin ve insanlığın timsali olarak resmedilen genç bir hayat kadını bulunmaktadır. Bu kadın da aynı Cornudet gibi istenmeyen yolcudur. Erken yaşında başlayan şişmanlığı nedeniyle lakabı Tombalak’tır (Yağ Tulumu’dur.) Yazar kadının hakir görüldüğüne 
vurgu yapmak için neredeyse öykünün sonuna kadar onu lakabıyla adlandırır. Diğer yolcuların isimleri, hatta kimilerinin şecerelerinin bile bilgisi verilirken, okur genç kadının adının Elisabeth Rousset olduğunu çok sonra öğrenir. Bu iki yolcu diğer altı yolcunun kendi aralarındaki çekişme ve çekememezliğin bir süreliğine de olsa kaybolmasına neden olur. Tahir N. Duran'ın ifadeleriyle, Erkekler arasında Cornudet'ye karşı oluşan ittifak para ve güç temellidir. 'Cournudet'nin orada bulunması bir tutuculuk içgüdüsüyle üç erkeği birbirine yaklaştırmıştı. Aralarında yoksullara karşı bir tür aşağı görme edasıyla konuşarak, paradan söz ediyorlardı [...] Üçü de birbirlerine hızlı ve dostça bakışlarla bakıyorlardı. Ayrı ayrı sınıflardan olmalarına karşın, para tutan ve ellerini ceplerine soktukları zaman altınları şakırdayan insanlar olarak, kendilerini para dayanışmasıyla kardeş duyumsuyorlardı." $(1946: 25,26)$ Bayanlar arasında Tombalak’a karşı oluşturulan ittifak da yasal aşkın yasak aşka tepeden bakmasından başka bir şey değildir. ' $\mathrm{Bu}$ şırfıntının orada bulunması yüzünden birdenbire dost ve adeta teklifsiz oluveren üç kadın aralarında konuşmaya başladılar, hayasızca kendini satan bu insan karşısında eşlik erdemlerini birleştirmeleri gerektiğini düşünüyorlardı. Çünkü yasal aşk yasal olmayana hep yukardan bakar." (1946: 25) Sürekli dua etmekle meşgul olan rahibeler başlangıçta bu gruplaşmadan uzaktırlar. Sözde 'saygın' diğer altı kişi arasındaki bu ittifak da çok sürmez. Şiddetli soğuk ve kar yağışı nedeniyle yolculuk beklenenden uzun sürmektedir. Zaten yola tedbirsiz çıkmış bulunan dokuz yolcu açlıktan başka bir şey düşünemez hale gelir. O ana kadar para, güç ve saygınlığı en büyük erdem olarak görenler, fahişe ve yüz karası olarak niteledikleri Tombalak'ın yanına paketler dolusu yiyecek almış olduğunu görünce birden paylaşmanın erdemlerini hatırlayıverirler. Tombalak ise içtenlik ve güler yüzle yiyeceğini onlarla paylaşır $(2001: 13,14)$. Okur yiyecek olayından sonra, genç kadının hem gerçek bir vatansever olduğundan hem de kendi şerefini korumak zorunda kaldığından evine yerleşmiş olan bir Alman subayına saldırdığı için Rouen'den kaçmakta olduğunu öğrenir. Yazar öykünün kahramanlarını tek tek ele alır, aralarındaki ilişkiyi, çelişkiyi ve düşüncelerini etraflıca anlatır. Olay örgüsünün düğümü ise konaklamak üzere uğradıkları Toles kentindeki bir handa çözülür. Yolcular ertesi gün tekrar yola koyulmaya hazırlanırken, oraya yerleşmiş olan bir Alman subayı tarafından alıkonulduklarını öğrenirler. Subay yolcuların yola devam etmelerine izin vermek için Tombalak'ın kendisiyle bir gece geçirmesini şart koşmuştur. Öykü, Alman askerine karşı tiksintiyle direnen Tombalak ile bir an evvel gitmek için sabırsızlanan diğer yolcular arasındaki gerilimle devam eder. Yine Duran'ın deyişiyle, sözde 'yüksek soylu' ve ‘yüksek ahlaklı' bu insanlar ilkin, kendileri yola devam edebilmek için Tombalak’ı orada bırakmayı önerirler. Ancak, onlar olmadan genç kadını elde edemeyeceğinin farkında olan subay tekliflerini kabul etmez. Bunun üzerine, soylulukları ve ahlakları ile her fırsatta övünenler kendi çıkarları uğruna Tombalak’1 Alman subayının koynuna girmeye ikna etmek için her yolu denerler. Son ana kadar tarafsız görünen rahibeler de araya girerek, 'Kilise kötü davranışları, Tanrı uğrunda yahut da insanlık için yapıldıkları takdirde kolayca bağışlar." (1946: 53) ve "'̇yi niyetle yapılan hiçbir şey Tanrı'yı gücendirmez." (1946: 53) şeklinde beyanlarda bulunurlar. Rahibelerin, Tanrı'nın böyle bir durumda genç kadından 
bunu yapmasını isteyeceğini de söylemeleri üzerine Tombalak'ın direnci tamamen kırılır. Dördünce günün sabahında araba tekrar yola çıkar. Daha bir gün önce, etrafında dönüp kaç türlü dil dökenler yola devam etmek üzere arabaya binildiğinde Tombalak’1 yine aşağılamaya başlarlar. Genç kadını kirli ve ahlaksız olduğu gerekçesiyle yok sayarlar. Kendi ahlaksızlıklarının hiç farkında olmaksızın, onun oturduğu tarafa başlarını çevirmekten bile adeta tiksinirler (2001: 14). Ne açlıktan ölmek üzere olduklarında onlarla paylaştı̆̆ 1 yemeğini ne de uğurlarına kendini kirletmek pahasına yapmış olduğu fedakârlığı hiç hatırlamadıklarını ve hiçbirinin ona bakmadığını, onunla ilgilenmediğini gören zavallı Tombalak ise yalnızca 'onu önce feda eden, sonra da gereksiz ve kirli bir şeymiş gibi bir yana atan bu namuslu alçakların aşağılamasından boğulur gibi olarak" (1946: 62) gizli gizli ağlar.

\section{Boule de Suif' in (Yă̆ Tulumu'nun) Toplumsal Yönü}

Görülüyor ki, Maupassant bu öyküde farklı toplumsal sınıflara ait karakterlerin şahsında bütün aristokrasi, burjuvazi ve ruhban sınıflarını eleştirmiştir. Usta öykücü, Tahsin Yücel'in deyimiyle, benzerine az rastlanır türden bir gözlem gücü ve küçük ayrıntıları değerlendirebilme yeteneği ortaya koymuştur. Doğrudan söylemenin gerisinde ince bir alayı sürdürürken, kişisel çıkar duygusunun derinliği karşısında yurt sevgisi, ulusal onur gibi duyguların ne kadar yüzeysel kaldığını ama bu yüzeysel duyguların yeri geldiğinde, kendi sınıfından olmayanı dışlamak ya da ezmek için ne denli güçlü bir silah olarak da kullanılabileceğini göstermiştir (1993: 29). O dönemde olduğu gibi şimdilerde ve insanlığın hemen her döneminde de bireysel çıkarlar ve sınıf farklılıkları söz konusu olduğunda bireyler acımasız, ikiyüzlü ve tahakkümcü olabilmektedir. Boule de Suif' de, bu acı ama evrensel gerçeğin usta bir dille gözler önüne seriliyor olması nedeniyle, eserin önemini ve popülerliğini hiçbir zaman kaybetmeyen yapıtların başında geldiği söylenebilir.

\section{Tartışma ve Sonuç}

Hiçbir çevirinin nedensiz, rastlantısal gerçekleşmediğini düşünmek olasıdır. Even-Zohar'ın da işaret ettiği gibi, çeviri edebiyat 'merkez' konumunda olduğunda çoğuldizgenin merkezinin biçimlendirilmesine etkin olarak katılıyor demektir ve böylelikle çeviri edebiyat da büyük ölçüde yenilikçi güçlerin bir parçası haline gelmektedir (Paker, 2008: 28). Türk tarihinde özellikle 1940 sonrası çeviri hareketiyle gerçekleşenin de bu olduğu ve Boule de Suif'in ise 1940 yılında Tercüme Bürosu'nun kurulmasıyla başlayan Türk tarihindeki ikinci çeviri hareketi kapsamında, Hasan Ali Yücel'in katkılarıyla Milli Eğitim Basımevi tarafından, ilk olarak, 1946 yılında Tombalak adıyla Nermin Sankur'un çevirisiyle Türkçeye kazandırılmasının böyle bir işlevi yerine getirdiği söylenebilir. Ancak, Türk tarihindeki bu örneğinin işaret ettiği türden yeni bir dil, kültür ve edebiyat oluşturmak gibi görünür nedenlerle başlatılmış büyük çeviri hareketleri yaşanmaksızın da yine bir takım toplumsal, ideolojik ve politik hedefler doğrultusunda çevirilerin girişinin ve dolaşımının devam ettiği görülmektedir. 
Çeviri de küresel çağın popüler kültürü kapsamında tercih edilen, erişimi kolay ve etkisi hızlı ürünler üzerinden görevini yerine getirmektedir. John Berger'in de ifade ettiği gibi, insan algısında en güçlü ve kalıcı etkiye sahip aracın resim yani görsellik olduğu (2011) kabul edilirse hem yazınsal hem de görsel nitelikli bir tür olarak çizgi romanın bu yüzyıldaki önemi belirginleşir. Tüm kitle iletişim araçlarını ve sanat yapıtlarını olduğu kadar çizgi romanları da toplumsal ve kültürel bağlamdan ayrı düşünmek olası görünmediğinden, ekonomik amaçlı olduğu kadar politik ve ideolojik amaçlı da üretilmekte oldukları gözlemlenebilir.

Özellikle son yıllarda, edebiyat klasiklerinin türlerinin de çevrilmesi, diğer bir deyişle, klasik eserlerin dönüştürülmesi yaygınlaşmıştır. Bu akımın amaçlarının ve gerekçelerinin adeta bir özetinin, Maupassant'ın ilk başyapıtı Boule de Suif' in Yağ Tulumu'na dönüşmesinin nedenleri incelendiğinde kendini gösterdiği düşünülebilir. Öykünün evrensel niteliği, her dönemdeki ve her coğrafyadaki insanın en sevimsiz gerçekliğine işaret ediyor olması onu, toplumsal bilinci uyandırma aracı olarak kullanılmaya elverişli kıldığı için eserin, popüler kültürün etkin ve yaygın araçlarından biri olan çizgi roman biçiminde yeniden üretildiği söylenebilir. Yă̆ Tulumu'nun alışılagelmiş çizgi roman özellikleri göstermiyor olması da bu savı doğrular nitelikte görünmektedir.

İlgili bölümde evvelce açıklanan çizgi roman türleri göz önüne alındığında, Yağ Tulumu'nun bir kahraman çizgi romanı değil, bir yaratıcı çizgi romanı olabileceği görülür. Yapıt; macera, aksiyon, mizah ya da korku gibi eğlence öğeleri içermez. Aksine, neredeyse her şeyin bir arabanın içinde yaşanması gibi bir durağanlık ve tekdüzelik söz konusudur. Süper kahramanlar yoktur. Kişiler de olay da sıradan hayatın gerçekliğiyle tam tamına örtüşür. Klasik çizgi romandaki temel iyi-kötü savaşından, her maceranın sonunda iyi olanın bir kez daha galip çıkması yerine, burada yenilen ve ezilen iyi olarak işaret edilendir. Böylelikle, sınıf farklılığının çarpıcı bir biçimde altı çizilmektedir. Ciddi bir toplum sorgulaması ve hâlâ varlığını, hâkimiyetini sürdürmekte olan aristokrat, burjuva ve ruhban sınıflarının eleştirisi söz konusudur.

\section{Son Notlar}

Tüm bunların 1şığında ve genellikle kahraman çizgi romanlarının egemen ideolojiye, yaratıcı çizgi romanlarının ise muhalif ideolojiye hizmet ettiği de göz önüne alındığında, Yăg Tulumu'nun karşı, muhalif ideolojiye hizmet ettiği çıkarımına varılabilir. Durumun kanıtı olabilecek bir diğer olgu da yapıttaki sınıf farklılığı temasının, sınıf bilincinin her şey olduğu; değişimin ve devrimin temelinin sınıf bilincini uyandırarak atılması gerektiği ve sınıf bilincini uyandırma amacına hizmet etmeyen sanatın sanat olmayacağı, çağrısını yapan Karl Marx’1 (2015) hatırlatmasıdır. Yağ Tulumu Marx'ın çağrısına uyanların, egemen kapitalist düzenin 'aracı mesaja, mesajı araca dönüştürerek' (McLuhan, 2015), bireyleri, dolayısıyla da toplumları, Jean Baudrillard'ın da vurguladığı gibi, kitle iletişim araçları ve sanat yapıtlarıyla popüler kültür adı altında yaratılan sınırsız bir tüketim ve haz mantığı doğrultusunda uyutup uyuşturmasına (2010: 121-241) bir tepkisi olarak değerlendirilebilir. Üstelik böyle yorumlandığında, ilginçtir ki, 'karş1 ateşlere karşı ateşler'i, 'onlarla onların silahlarıyla savaşmayı' öneren Pierre Bourdieu'nün 
de (2006: 9, 11-18, 57-63) izinden gidilmiş olduğu sonucuna ulaşılabilir. Kahraman çizgi romanını kullananların; yani geçmişte resmi ve görselliği eğitimsiz alt sınıfı kendi istekleri doğrultusunda yönetmek amacıyla kullanmış olan üst sınıfın mirasçılarının karşısında bugün, yine aynı oranda resim ve görsellik içeren (onların bir aracını, bir yöntemini içeren) yaratıcı çizgi romanını kullananlar yer almaktadır.

\footnotetext{
Hakem Değerlendirmesi: Dış bağımsız.

Çıkar Çatışması: Yazar çıkar çatışması bildirmemiştir.

Finansal Destek: Yazar bu çalışma için finansal destek almadığını beyan etmiştir.

Peer-review: Externally peer-reviewed.

Conflict of Interest: The author has no conflict of interest to declare.

Grant Support: The author declared that this study has received no financial support.
}

\section{KAYNAKÇA/REFERENCES}

Baudrillard, J. (2000). Tüketim Toplumu. (Çev. F. Keskin, N. Tutal). İstanbul: Ayrıntı Yayınları. (Orijinal yayın tarihi, 1970)

Berger, J. (2011). Görme Biçimleri. (Çev. Y. Salman). İstanbul: Metis Yayınları. (Orijinal yayın tarihi, 1972) Bogenç Demirel, E. (2008). Guy de Maupassant Traductions, Turquie. Benhamou,Y. Leclerc, E. Vincent, Bibliographie Des Ecrivains Français içinde (635-655. ss.). Roma; Paris: Memini.

Bourdieu, P. (2006). Karşı Ateşler. (Çev. H. Yücel). İstanbul: Yapı Kredi Yayınları.

Cantek, L. (2012). Türkiye'de Çizgi Roman. İstanbul: İletişim Yayınları.

Duran, T. N. (2009). Yüz Otuz Y1l Sonra Bugünü Anlatan Bir Öykü: Tombalak. Evrensel Kültür, 113, $13-14$.

Even-Zohar, I. (1990). Polysystem Studies. Poetics Today, 11(1), 9-247.

Gürçağlar Tahir, Ş. (2008). Tercüme Bürosu Nasıl Doğdu. Birinci Türk Neşriyat Kongresi ve Çeviri Planlaması. M. Rifat, Çeviri Seçkisi I Çeviriyi Düşünenler içinde (37-43. ss.). İstanbul: Sel Yayıncılık.

Gürsel, N. (1995). Uygarlık ve Çeviri. Cumhuriyet Dönemi Türkiye Ansiklopedisi içinde (Cilt II, $320-323$. ss.). İstanbul: İletişim Yayınları.

İnce, E. (2001). Maupassant Üzerine. II. Frankofoni Kurultayı Cumhuriyet Üniversitesi Sivas 17-18 Mayıs 2001 Bildiriler Kitabı içinde (211-212. ss.).

Karantay, S. (2008). Tercüme Bürosu: Normlar ve İşlevler. M. Rifat, Çeviri seçkisi I Çeviriyi Düşünenler içinde (48-54. ss.). İstanbul: Sel Yayıncılık.

Kudret, C. (2008). İlk Adım: Çeviri. M. Rifat, Çeviri seçkisi I Çeviriyi Düşünenler içinde (19-21. ss.). İstanbul: Sel Yayıncilik.

Lefevere, A. (1998). Translation Practice(s) and the Circulation of Cultural Capital: Some Aeneids in English. S. Bassnet ve A. Lefevere, Constructing Cultures. Essays on Literary Translation içinde (41-56. ss.). Clevedon and Philedelphia etc.: Multilingual Matters.

Marx, K. (2015). Kapital Cilt 1,2,3. (Çev. M. Selik, E. Özalp). İstanbul: Yordam Kitap. (Orijinal yayın tarihi, 1867) Maupassant, G. (1993). Boule de Suif, Mademoiselle Fifi. Paris: Maxi-Poche Bookking International.

Maupassant, G. (1946). Tombalak. (Çev. N. Sankur). Ankara: Milli Eğitim Basımevi. (Orijinal yayın tarihi, 1880) 
Maupassant, G. (2010). Yağ Tulumu. (Çev. N. S. Danışman). İstanbul: Everest Yayınları Çizgi Serisi: 9.

McLuhan, M. (2015). Yaradanımı Medya - Medium is the Message. (Çev. Ü. Oskay). İstanbul: Turkuvaz Kitap. (Orijinal yayın tarihi, 1967)

Paker, S. (2008). Tanzimat Döneminde Avrupa Edebiyatından Çeviriler, Çoğuldizge Kuramı Açısından Bir Değerlendirme. M. Rifat, Çeviri seçkisi I Çeviriyi Düşünenler içinde (22-32. ss.). İstanbul: Sel Yayıncılık. Venuti, L. (1995). The Translator's Invisibility. A History of Translation. London; New York: Routledge.

Wolf, M. (2007). Introduction. The Emergence of a Sociology of Translation. M. Wolf ve A. Fukari (Ed), Constructing a Sociology of Translation, Vol 74 içinde (1-36. ss.). Amsterdam; Philadelphia: Benjamin Publishing Company.

Yücel, T. (1993). Ölümünün 100. Yılında Guy de Maupassant, Maupassant Tüm Yapıtlarını Yaşamının Son On Yılına Sığdırdı. Milliyet Sanat, Sayı 314 (BDK) (C.5275), 1993, 28-29. 